\title{
Architectural design and acute psychiatric care
}

\author{
Rizwan Taj and John Sheehan
}

\begin{abstract}
All stafl based in a newty bullt acute psychiatilic unit for more than six months were asked about the dimiculties they encountered in the implementation of their duties and what changes they recommended. The problem areas identified included poor design and location of nursing observation station, lack of proper seclusion faciltitios, insuficient ventilation, unsafe position of the roof garden, exposed beams and supports, proximity to the lake and inadequate interview facillities for all staff. The urgent recommendations included alteration in the design and positioning of observation station, improving ventilation, making the roof garden safe, and covering all exposed beams and supports. The desirable changes included extra interviewing facillities and a spacious observable television room. Consultation by mental health professionals during the initiol stage of designing of poychiatilic units is escential.
\end{abstract}

The Irish Green Paper on Mental Health (Department of Health, 1992) advocated the development of a community based psychiatric service.

The Eastern Health Board set out its psychiatric policy in the report Development of $a$ Community Psychiatric Service which outlines the strategy for the development of community services, whereby the community is seen as the service base while accepting that small acute units need to be established in general hospitals. The nature of these units is of considerable importance and it is vital that they are properly designed and equipped to deal with acute psychiatric problems.

Goh et al (1989) found that $88 \%$ of in-patients committing suicide used violent methods such as hanging and jumping. Crammer (1984), in his explanations for 'epidemics' of suicide in UK hospitals, included poor observation on wards because of physical design.

Given the importance of design there is a deficiency of information or advice on the building of psychiatric units. Barefoot (1992) believes that the worst place to bulld an acute psychiatric factlity is in a medical or surgical ward of a general hospital.

A modern 30-bed acute open psychiatric unit was opened in a general hospital in January 1992. Various incidents have questioned its suitability for acute psychiatric care. The design of the unit was implemented by a team involving administrative staff and architects. At no stage of the construction was any mental health professional consulted. Because of our concern over the suitability of the new unit for managing acute psychiatric disorders we conducted this study.

The main aims of the study were to document shortcomings in the design which created difficulty in the implementation of duties by the staff; and to compile a list of recommendations for both urgent/necessary and desirable change.

\section{The unit}

The unit was built as a satellite extension of the general hospital connected by link corridors. These are two storeys. The ground floor (Fig. la) has 30 beds, a TV room, a nurses' office, a clinic room, a doctor's room and bathrooms. There are two six-bedded rooms facing the nursing counter, three four-bedded rooms on the side and the rest are single rooms. On the first floor are consultants' offices, offices for the other staff, the patients' dining room, relaxation room and library. There are also rooms for occupational therapy and lastly an attractive roof garden.

\section{The policy}

The health service policy is to treat as many patients as possible in their own homes or in the community. Only those unmanageable in the community were admitted. Patients admitted therefore tend to be very ill, often psychotic and with high suicide risk. Approximately $10 \%$ are admitted on an involuntary basis.

\section{The study}

A questionnaire was formulated regarding the design of the unit asking each staff member:

(a) What difficulties have you encountered in the implementation of your duties?

(b) What changes do you recommend? Urgent/necessary/desirable.

This was circulated to all 30 medical and nursing staff who have been based in the unit for a 
period of more than six months. The response rate was $90 \%$.

\section{Findings}

The following problem areas were identified

\section{Nursing observation station}

Location. This did not give an unimpeded view of the entrance to the unit and furthermore all emergency exits were hidden from it.

Design. It was open on both sides and did not have a protective screen. It was not possible to conduct a private conservation on the counter telephone.

\section{Seclusion facilities}

There was a lack of seclusion facilities. One of the single rooms had been converted for seclusion purposes but this was not appropriate. Obser-

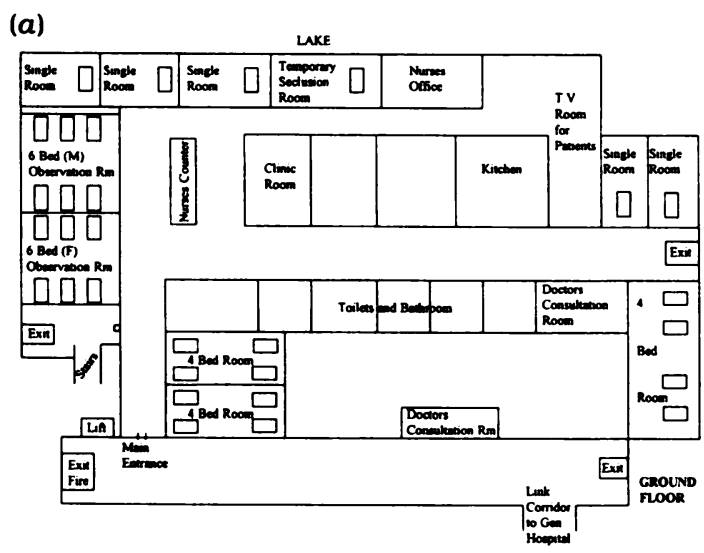

(b)

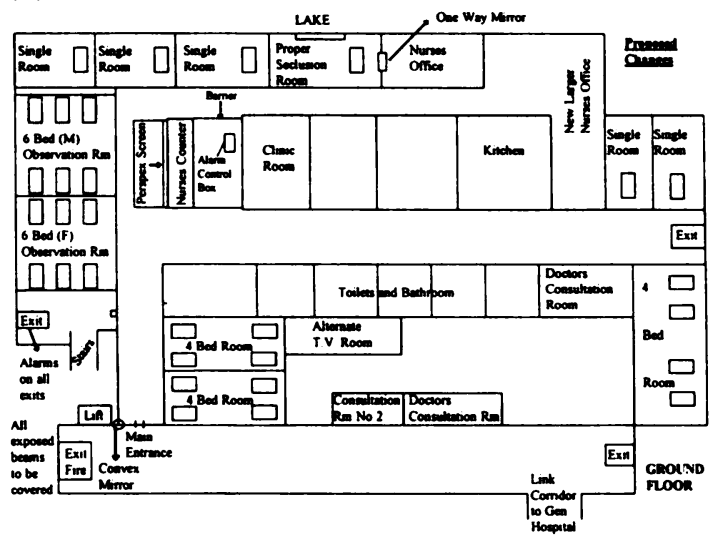

Fig. 1. Psychiatric in-patient unit: (a) current design; (b) proposed changes. vation from the observation position station was not possible. The exposed radiator was unsafe.

\section{Ventilation}

Ventilation of the unit was insufficient. The majority of psychiatric patients smoke and smoking is normally allowed in psychiatric units. The staff were wary of the danger of passive smoking.

\section{Roof garden}

Although nicely laid out it had limited use because of its positioning. Its presence on the first floor made it unsafe and an ideal place for 'jumpers'.

\section{Exposed beams and supports}

Throughout the structure there were many exposed beams and supports which might prove unsafe for patients with ideas of hanging themselves.

\section{The lake}

A man-made lake is situated close to the unit. Proximity to the lake was a major source of discomfort for the staff. Only a few in-patients with suicidal ideas had failed to mention the desire for 'a dip in the lake'. On occasion, patients with suicidal intent had been brought back to the unit on their way to the lake. It demanded a persistent state of hypervigilance and created anxiety if a patient was found missing.

\section{Office space}

There are inadequate interview facilities for all staff, junior and senior.

TV room

The patients' TV room is small and in a place where observation of patients is not possible.

\section{Recommendations}

Several recommendations based on the problems identified were made (Fig. 1b). The necessary/ urgent ones included:

(a) alteration of the nursing station, including a change of positioning to improve observation of patients and structural changes to improve its safety and privacy

(b) an alarm system to be fitted on all exits

(c) proper seclusion rooms

(d) improving the ventilation of the unit with the help of vents in appropriate places and 
further restriction of smoking to some areas

(e) making the roof garden area safe by erecting barriers on all potential jump areas

(f) covering all exposed beams and supports throughout the structure.

The desirable changes included

(a) extra interviewing facilities were needed for all staff in the unit. This is not something that can be shared although timetabling can allow for multiple usage

(b) a spacious observable TV room to be constructed for the patients.

The unused space of the long link corridors could be utilised for these purposes.

\section{Comment}

Analysis of the information gathered clearly indicated that the unit in its present state is not ideal for the management of acute psychiatric patients. Considerable change is needed to increase the suitability of the unit and could involve extra finances. Most problems could be overcome by improving the design of the unit.

This study offers a warning to clinicians on the importance of being involved at an early stage in the brief to architects on the design of any building in which they are likely to be working. This advice applies to hospitals but also to mental health centres and other community facilities which are likely to be much more commonly offered. The siting and external appearance of the building as well as the internal design may have considerable relevance to psychiatric care.
Another aspect which did not emerge in the replies to the questionnaire is the furnishing and general environment of the unit. It is important to have a more domestic and reassuring, rather than clinical or 'sterile', setting in psychiatry.

\section{Conclusion}

Consultation by mental health professionals during the initial stage of designing of psychiatric units is essential and will save direct and indirect costs, direct from implementation of changes and indirect due to the need for extra nursing staff.

\section{References and further reading}

APPLEBY, L. (1992) Suicide in psychiatric patients: risk and prevention. British Journal of Psychiatry 161, 749-758.

BAREFOOT. P. (1992) Psychiatric wards in DGHs. An architect's comments. Psychiatric Bulletin, 16, 99-100.

CRAMmer. J.L. (1984) The spectal characteristics of suicide in hospital in patients. British Journal of Psychiatry. 146. $460-476$.

DepartMent OF Health (1992) Green Paper on Mental Health. 11-19.

Gale, S.W., Mesnikoff, A., Fine, J. et al (1980) A study of suicide in state mental hospitals in New York City. Psychiatric Quarterly. 62, 201-213.

GoH, S.E.. SAlmons, P.H. \& Whitrington, R.M. (1989) Hospital suicides: are there preventable factors? Profile of psychiatric hospital suicide. British Journal of Psychiatry. 164, 247-249.

*Rizwan Taj, Liaison Registrar; and John Sheehan, Sentor Registrar, Kildare Mental Health Service, Eastern Health Board, Kildare, Ireland

-Correspondence: Trinity Court, 30-31 Pearse Street. Dublin 2, Republic of Ireland 